Published in final edited form as:

J Chromatogr B Analyt Technol Biomed Life Sci. 2017 February 15; 1044-1045: 127-131. doi:10.1016/ j.jchromb.2017.01.008.

\title{
Analysis of $\boldsymbol{N}^{\prime}$-Nitrosonornicotine Enantiomers in Human Urine by Chiral Stationary Phase Liquid Chromatography- Nanoelectrospray lonization-High Resolution Tandem Mass Spectrometry
}

\author{
Jing Yang, Steven G. Carmella, and Stephen S. Hecht ${ }^{*}$ \\ Masonic Cancer Center, University of Minnesota, Minneapolis, MN 55455, USA
}

\begin{abstract}
We have developed a chiral stationary phase liquid chromatography-nanoelectrospray ionizationhigh resolution tandem mass spectrometry (LC-NSI-HRMS/MS) method to investigate the enantiomeric composition of low parts per trillion amounts of the carcinogen $N^{\prime}$ -

nitrosonornicotine (NNN) in the urine of cigarette smokers and smokeless tobacco users. ( $S$ )-NNN is the major enantiomer in tobacco and is more carcinogenic than $(R)$-NNN in rats, but no data are available on the enantiomeric composition of NNN in humans. The method used $\left[{ }^{13} \mathrm{C}_{6}\right] \mathrm{NNN}$ as an internal standard and [pyridine- $\mathrm{D}_{4}$ ]nornicotine to monitor possible artifactual formation of $\mathrm{NNN}$, which was found to be less than $2 \%$ of the quantified NNN. The enantiomeric composition of NNN $(20.5 \pm 27.1 \mathrm{fmol} / \mathrm{ml}$ urine $)$ in 20 cigarette smokers was $67 \pm 5 \%(S)$-NNN while that in 10 smokeless tobacco users $(67.1 \pm 56.7 \mathrm{fmol} / \mathrm{ml}$ urine) was $56 \pm 3 \%(S)$-NNN. These results demonstrate that the highly carcinogenic $(S)$-NNN is the major enantiomer in human urine, and that the enantiomeric composition of NNN in human urine is remarkably similar to that in cigarette smoke and smokeless tobacco. This is the first study to combine chiral stationary phase separations with nanoelectrospray ionization and high resolution tandem mass spectrometry to quantify trace levels of enantiomeric metabolites in human urine.
\end{abstract}

\section{Keywords}

$N^{\prime}$-Nitrosonornicotine; enantiomeric composition; chiral separation; smoker's urine; smokeless tobacco user's urine; chiral stationary phase liquid chromatography-nanoelectrospray ionizationhigh resolution tandem mass spectrometry

\section{Introduction}

$N^{\prime}$-Nitrosonornicotine (NNN) is a strong carcinogen believed to be an important causative agent for esophageal and oral cancers in smokers and smokeless tobacco users [1-3]. This

\footnotetext{
*To whom correspondence should be addressed: Masonic Cancer Center, University of Minnesota, $22316^{\text {th }}$ Street SE - 2-148 CCRB, Minneapolis, MN 55455, USA. phone: (612)624-7604 fax: (612)624-3869 hecht002@umn.edu.

Publisher's Disclaimer: This is a PDF file of an unedited manuscript that has been accepted for publication. As a service to our customers we are providing this early version of the manuscript. The manuscript will undergo copyediting, typesetting, and review of the resulting proof before it is published in its final citable form. Please note that during the production process errors may be discovered which could affect the content, and all legal disclaimers that apply to the journal pertain.
} 
tobacco-specific nitrosamine is present in virtually all tobacco products and is formed mainly upon nitrosation of the corresponding tobacco alkaloid nornicotine during tobacco curing and processing $[4,5]$. NNN has a chiral center at its $2^{\prime}$ position; $(S)$-NNN (1, Figure 1 ) is the major enantiomer in tobacco products. An earlier study showed that $(S)$-NNN comprised $75 \%$ of the total NNN in a small set of cigarettes and conventional smokeless tobacco products [6]. In a recent more extensive study, the average amount of (S)-NNN in tobacco was $63 \%$, including $67 \%$ in cigarette tobacco and $57 \%$ in conventional moist snuff products [7]. The enantiomeric composition of NNN was essentially the same in cigarette smoke as in cigarette tobacco [7].

(S)-NNN is a powerful carcinogen in rats, inducing 89 oral cavity tumors and 122 esophageal tumors in 20 rats upon administration in the drinking water at a dose of $14 \mathrm{ppm}$ for 17 months. $(R)$-NNN had relatively weak carcinogenic activity in that study [8]. While the metabolism of the NNN enantiomers has been studied in vitro with human cytochrome P450 enzymes and in vivo in laboratory animals [9-11], there are no published data on the enantiomeric composition of NNN in humans. Approximately $1 \%$ of the NNN dose in smokers is excreted in the urine as unchanged $\mathrm{NNN}$ and $\mathrm{NNN}-\mathrm{N}$-glucuronide, collectively termed total NNN [12]. Total NNN is a useful biomarker of carcinogen exposure and cancer risk associated with the use of tobacco products [3, 12-16]. The goal of the study reported here was to determine the enantiomeric composition of urinary total NNN in smokers and smokeless tobacco users. This could provide potentially valuable information pertinent to the metabolism of NNN in humans and the carcinogenic hazards associated with use of tobacco products. The analysis of NNN enantiomers in human urine is quite challenging for several reasons. First, baseline resolution of the enantiomers must be achieved. Second, the amount of each NNN enantiomer present in the urine of people who use tobacco products will typically be about $1-10$ ppt $[12,15]$. Third, artifactual formation of NNN can easily occur during analysis and must be monitored $[12,15]$.

Previously, NNN enantiomers in tobacco products were analyzed by chiral stationary phase gas chromatography coupled with thermal energy analysis (GC-TEA) or mass spectrometry (GC-MS) [5, 6]. Capillary electrophoresis has also been used to perform the chiral separation with the assistance of cyclodextrin [17]. However, more sensitive techniques and instrumentation are needed to quantify the extremely low levels of unchanged NNN enantiomers excreted in human urine. Liquid chromatography-tandem mass spectrometry (LC-MS/MS) has been used to quantify trace urinary racemic total NNN levels [3, 14, 15]. For the special requirements of this study, we developed a chiral stationary phase liquid chromatography-nanoelectrospray ionization-high resolution tandem mass spectrometry (LC-NSI-HRMS/MS) method for analysis of the enantiomeric composition of NNN in human urine.

\section{Materials and methods}

\subsection{Materials}

We purchased racemic [pyridine- $\left.\mathrm{D}_{4}\right] \mathrm{NNN}$ and $\left[{ }^{13} \mathrm{C}_{6}\right] \mathrm{NNN}$ from Cambridge Isotope Laboratories (Andover, MA), and racemic NNN and [pyridine- $\mathrm{D}_{4}$ ]nornicotine from Toronto Research Chemicals (Ontario, Canada). $(R)$-NNN and $(S)$-NNN were synthesized [8]. 
Recombinant $\beta$-glucuronidase from E. coli was purchased from Sigma-Aldrich (St. Louis, MO). Phosphate buffered saline was purchased from Invitrogen (Grand Island, NY). All other chemicals and reagents were from Sigma-Aldrich, Fisher Scientific (Waltham, MA) or Alfa Aesar (Ward Hill, MA). ISOLUTE Supported Liquid Extraction (SLE+) diatomaceous earth cartridges were obtained from Biotage (Charlotte, NC). Oasis mixed-mode reversephase/strong cation-exchange (MCX) cartridges were from Waters (Milford, MA) and Bond Elut SI silica cartridges were from Agilent Technologies (Santa Clara, CA).

\subsection{Urine samples}

These studies were approved by the University of Minnesota Institutional Review Board. NNN enantiomers were measured in the urine of 20 cigarette smokers and 12 smokeless tobacco users. The urine samples from cigarette smokers were baseline samples obtained from 2010 to 2011 through the Biorepository of the University of Minnesota Tobacco Research Programs, which was established to collect biological samples for tobacco-related biomarker analysis and development. The 20 subjects smoked an average of $15 \pm 5$ cigarettes per day, and their demographic information (gender and age) was also collected. The 12 smokeless tobacco users were a subset of a previous study to determine toxicant exposure across brands of smokeless tobacco [18]. Ten subjects used conventional brands of moist snuff products, using an average of $11 \pm 6 \mathrm{~g}$ of tobacco product per day, and an additional 2 subjects used novel Camel snus products, using an average of $4 \mathrm{~g}$ of tobacco product per day. Pooled nonsmokers' urine samples used as negative controls were obtained from 6 volunteers recruited at the Masonic Cancer Center, University of Minnesota.

\subsection{Sample preparation}

The urine samples were partially purified according to a protocol previously validated with respect to accuracy, precision, and analyte stability, with some modifications [15]. The urine samples (stored at $-20^{\circ} \mathrm{C}$ prior to analysis) were thawed at $4{ }^{\circ} \mathrm{C}$ overnight and $3 \mathrm{~mL}$ aliquots were added into $10 \mathrm{~mL}$ glass centrifuge tubes (Kimble Chase, Vineland, NJ) with $200 \mathrm{pg}(1.1 \mathrm{pmol})$ racemic $\left[{ }^{13} \mathrm{C}_{6}\right] \mathrm{NNN}$ as the internal standard. We have previously observed that nornicotine in smokers' urine can be nitrosated during sample purification [15], so we added $2500 \mathrm{ng}(16.4 \mathrm{nmol})$ racemic [pyridine- $\mathrm{D}_{4}$ ]nornicotine to monitor the artifactual formation of NNN from nornicotine; precautions were taken to minimize this effect. The urine samples were then incubated overnight at $37{ }^{\circ} \mathrm{C}$ with $8000 \mathrm{U}$ of $\beta$ glucuronidase in PBS buffer (pH 7.4) to convert NNN- $N$-glucuronide to free $\mathrm{NNN}$, along with $5 \mathrm{mg}$ ammonium sulfamate to scavenge any nitrite that might be present and inhibit artifactual nitrosamine formation [19]. The samples were then adjusted to $\mathrm{pH} 4.8$ with 400 $\mu \mathrm{L}$ of $1 \mathrm{M}$ sodium acetate buffer ( $\mathrm{pH} 4.8$ ) and loaded onto the $5 \mathrm{~mL}$ Biotage ISOLUTE SLE + cartridges. The analytes were eluted with $20 \mathrm{~mL} \mathrm{CH}_{2} \mathrm{Cl}_{2}$ and dried under vacuum at room temperature in a SpeedVac concentrator (Thermo Scientific, San Jose, CA). The pH of the samples was lowered to 4.8 to protonate as much nornicotine as possible and prevent its extraction into the organic phase. Ammonium sulfamate $(5 \mathrm{mg})$ was also added to the eluent during the drying step to further prevent artifactual nitrosation. The dried samples were redissolved in $1 \mathrm{~mL} \mathrm{H}_{2} \mathrm{O}$, acidified with $500 \mu \mathrm{L}$ of $1 \mathrm{~N} \mathrm{HCl}$, and further purified on Oasis MCX cartridges $\left(60 \mathrm{mg}, 3 \mathrm{~mL}\right.$ ). After preconditioning the cartridges with $\mathrm{CH}_{3} \mathrm{OH}$ and $\mathrm{H}_{2} \mathrm{O}$, the samples were loaded, the cartridges were washed successively with $5 \mathrm{~mL}$ of $1 \mathrm{~N} \mathrm{HCl}, 5$ 
$\mathrm{mL} \mathrm{CH} 3 \mathrm{CH}_{3} \mathrm{OH}$ and $5 \mathrm{~mL}$ of 90:5:5 $\mathrm{H}_{2} \mathrm{O}: \mathrm{CH}_{3} \mathrm{OH}: \mathrm{NH}_{4} \mathrm{OH}$ (v:v:v) before the analytes were eluted with $5 \mathrm{~mL}$ of 35:60:5 $\mathrm{H}_{2} \mathrm{O}: \mathrm{CH}_{3} \mathrm{OH}: \mathrm{NH}_{4} \mathrm{OH}$ (v:v:v). The eluent was dried overnight in a SpeedVac concentrator and then redissolved in $100 \mu \mathrm{L}$ tetrahydrofuran and $900 \mu \mathrm{L}$ $\mathrm{CHCl}_{3}$ for the third purification step. Bond Elut SI cartridges $(100 \mathrm{mg}, 10 \mathrm{~mL})$ were preconditioned with $3 \mathrm{~mL} \mathrm{CHCl}_{3}$, and then the samples were loaded. The cartridges were washed with $1 \mathrm{~mL} \mathrm{CHCl}, 1 \mathrm{~mL}$ of 50:50 hexane:ethyl acetate (v:v), and finally eluted with $3 \mathrm{~mL}$ ethyl acetate. The eluent was dried and then transferred into $300 \mu \mathrm{L}$ fused insert vials (ChromTech, Apple Valley, MN) with $300 \mu \mathrm{L} \mathrm{CH}_{3} \mathrm{OH}$. The final sample was concentrated to dryness and stored at $-20^{\circ} \mathrm{C}$ until LC-NSI-HRMS/MS analysis. Two $\mathrm{H}_{2} \mathrm{O}$ blanks and two pooled nonsmokers' urine samples were included with each set of samples as negative controls and handled similarly.

\subsection{LC-NSI-HRMS/MS analysis of (R)-NNN and (S)-NNN in urine}

The worked-up samples were reconstituted in $30 \mu \mathrm{L}$ of $\mathrm{H}_{2} \mathrm{O}$ immediately before analysis, and $1 \mu \mathrm{L}$ was injected onto a nanoHPLC column (75 $\mu \mathrm{m}$ i.d., $360 \mu \mathrm{m}$ o.d., $17 \mathrm{~cm}$ length, and $15 \mu \mathrm{m}$ orifice) hand-packed with Pirkle Covalent $(S, S)$-Whelk-O1 Kromasil chiral stationary phase ( $5 \mu \mathrm{m}$, Regis Technologies, Morton Grove, IL) in a commercially available fused silica emitter (New Objective, Woburn, MA). The chiral nanoHPLC column was installed on a Dionex Ultimate 3000 RSLCnano HPLC system coupled to an Orbitrap Fusion Tribrid mass spectrometer (Thermo Scientific, San Jose, CA) for the separation and quantitation of the NNN enantiomers. The samples were first loaded onto the nanoHPLC column through a $5 \mu \mathrm{L}$ injection loop with $5 \% \mathrm{CH}_{3} \mathrm{OH}$ in $5 \mathrm{mM} \mathrm{NH}_{4} \mathrm{OAc}$ buffer at a flow rate of $1 \mu \mathrm{L} / \mathrm{min}$ for $5.5 \mathrm{~min}$. The flow rate was then reduced to $300 \mathrm{~nL} / \mathrm{min}$ in $0.5 \mathrm{~min}$ and the gradient was ramped to $40 \% \mathrm{CH}_{3} \mathrm{OH}$ over 4 min, followed by a slow gradient from $40 \%$ to $50 \% \mathrm{CH}_{3} \mathrm{OH}$ over 19 min for the separation of the enantiomers. After a 3-min wash at $95 \% \mathrm{CH}_{3} \mathrm{OH}$, the column was re-equilibrated to $5 \% \mathrm{CH}_{3} \mathrm{OH}$ at $1 \mu \mathrm{L} / \mathrm{min}$ for $6 \mathrm{~min}$. The following ion transitions were monitored with the accurate mass extracted: $m / z 178.1[\mathrm{M}+\mathrm{H}]^{+}$to $148.0995[\mathrm{M}+\mathrm{H}-\mathrm{NO}]^{+}$for $\mathrm{NNN}, \mathrm{m} / z 182.1$ to 152.1246 for [pyridine- $\left.\mathrm{D}_{4}\right] \mathrm{NNN}$, and $\mathrm{m} / \mathrm{z}$ 184.1 to 154.1196 for $\left[{ }^{13} \mathrm{C}_{6}\right] \mathrm{NNN}$. The precursor ions were isolated by a quadrupole with an isolation width of $\mathrm{m} / \mathrm{z} 1.5$ and fragmented by high-energy collision dissociation (HCD) at $13 \%$ collision energy, and the resulting fragment ions were detected by the Orbitrap detector set to a resolution of 60,000 . The ion source was operated in positive ion mode with a spray voltage of $2500 \mathrm{~V}$, and the ion transfer tube was set at $300{ }^{\circ} \mathrm{C}$.

\subsection{Calibration standards and quantitation}

Six calibration standards were prepared in $\mathrm{H}_{2} \mathrm{O}$ to cover the range of NNN levels expected in urine samples. Each standard solution contained racemic NNN and racemic [pyridine$\left.\mathrm{D}_{4}\right] \mathrm{NNN}$ at varying concentrations $(0.01,0.05,0.25,0.5,1$, and $5 \mathrm{pg} / \mu \mathrm{L}$ each $)$, and each solution contained racemic $\left[{ }^{13} \mathrm{C}_{6}\right] \mathrm{NNN}$ at $0.5 \mathrm{pg} / \mathrm{uL}$ as the internal standard. Linear calibration curves were constructed for $(R)$-NNN, $(S)$-NNN, $(R)$-[pyridine- $\left.\mathrm{D}_{4}\right] \mathrm{NNN}$, and $(S)$-[pyridine- $\left.\mathrm{D}_{4}\right] \mathrm{NNN}$ by plotting the corresponding peak area ratio against the concentration ratio, with respect to $(R)-\left[{ }^{13} \mathrm{C}_{6}\right] \mathrm{NNN}$ or $(S)-\left[{ }^{13} \mathrm{C}_{6}\right] \mathrm{NNN}$. Quantitation of each enantiomer was calculated by relating the measured peak area ratio to the slope of the calibration curve and the known internal standard amount. 


\subsection{Statistical analysis}

The $t$-test was used for the comparisons between cigarette smokers and smokeless tobacco users. The tests were conducted at a 5\% level of significance and the two-tailed $p$ values were calculated.

\section{Results}

Typical LC-NSI-HRMS/MS chromatograms of urine samples from cigarette smokers and smokeless tobacco users are shown in Figure 2. Three ion transitions were monitored corresponding to loss of the nitroso group from NNN, [pyridine- $\left.\mathrm{D}_{4}\right] \mathrm{NNN}$, or $\left[{ }^{13} \mathrm{C}_{6}\right] \mathrm{NNN}$. Separation of the two enantiomers was successfully achieved with the first eluting peak $\left(t_{\mathrm{R}}=\right.$ $\sim 21 \mathrm{~min}$ ) being the $(R)$-enantiomer followed by the $(S)$-enantiomer eluting around $22 \mathrm{~min}$. The peak identities were confirmed by comparing their retention times to those of enantiomerically pure standards injected separately. The two enantiomeric peaks of the added racemic internal standard $\left[{ }^{13} \mathrm{C}_{6}\right] \mathrm{NNN}$ exhibited slightly different peak areas due to the different ion suppression and matrix effects that occurred during the LC-NSI-HRMS/MS analysis. Since they co-eluted with the analyte peaks, this isotopically-labeled internal standard would take into account any differences in matrix effects or in recovery.

The middle trace showed two clear peaks for [pyridine- $\left.\mathrm{D}_{4}\right] \mathrm{NNN}$ artifactually nitrosated from the $2500 \mathrm{ng}$ spiked [pyridine- $\mathrm{D}_{4}$ ] nornicotine during the sample preparation [15]. The formation of $(S)$ - and $(R)$-[pyridine- $\left.\mathrm{D}_{4}\right] \mathrm{NNN}$ was also quantitated using the peak area ratio of the [pyridine- $\left.\mathrm{D}_{4}\right] \mathrm{NNN}$ to the corresponding $\left[{ }^{13} \mathrm{C}_{6}\right] \mathrm{NNN}$ internal standard. Both $(S)$ - and $(R)$-[pyridine- $\left.\mathrm{D}_{4}\right]$ nornicotine were nitrosated to approximately the same extent, and the differences in peak areas were likely due to different ion suppression and matrix effects, which was corrected by the use of isotope dilution. Overall, the average artifactual conversion rate was minimal: $0.00005 \pm 0.00007 \%$ for cigarette smokers' urine and 0.00004 $\pm 0.00002 \%$ for smokeless tobacco users' urine. The urine samples were also analyzed for nornicotine (averaged $151 \pm 89 \mathrm{ng} / \mathrm{mL}$ ) by the laboratory of Professor Sharon E. Murphy [20] and we estimate that artifactual formation of NNN from urinary nornicotine contributed to only $0.1-1.7 \%$ of total NNN measured. This assures the analysis of NNN enantiomers as they exist in urine rather than artifactually formed from urinary nornicotine during the sample preparation.

The urinary NNN enantiomeric composition for cigarette smokers and smokeless tobacco users using conventional moist snuff products is summarized in Table 1. (S)-NNN was the major enantiomer excreted in the urine, averaging $67 \%$ for cigarette smokers and $56 \%$ for conventional moist snuff users. The percentage of $(S)$-NNN was significantly higher in cigarette smokers than in conventional smokeless tobacco users $(p<0.001)$. The amount of total NNN was significantly higher in conventional smokeless tobacco users than in cigarette smokers $(p=0.005)$. The two Camel snus users had 60\% $(S)$-NNN in their urine.

\section{Discussion}

We have for the first time determined the enantiomeric composition of NNN in the urine of cigarette smokers and smokeless tobacco users. The use of chiral stationary phase LC-NSI- 
HRMS/MS was critical for the success of this project, as it provided the requisite enantiomer separation, sensitivity, and specificity for clear analysis of the extremely low levels of NNN enantiomers in human urine. While previous studies have described the analysis of urinary enantiomeric metabolites using LC-MS/MS techniques [21, 22], this is apparently the first study to combine chiral stationary phase separations with nanoelectrospray ionization and high resolution MS/MS to quantify trace levels of enantiomeric metabolites in human urine. Furthermore, use of a monitor amine, [pyridine- $\mathrm{D}_{4}$ ] nornicotine, gave us confidence that artifact formation during analysis was minimal. This is critical because artifactual formation of NNN during analysis would have produced excessive amounts of ( $S$ )-NNN (from $(S)$ nornicotine in urine) as found in our initial experiments (data not shown).

The enantiomeric composition of NNN in urine was remarkably similar to that of the NNN in the products used by our subjects. We compared the results of the current study on the urinary enantiomer composition to the Stepanov study in 2013 on the enantiomeric composition of NNN in tobacco products since the urine samples were collected at about the same time (2010-2011) that the tobacco products were purchased and in the same location (Minneapolis) [7, 18]. Moreover, in the case of smokeless tobacco users, these subjects used the same brands of products as in the Stepanov 2013 study [7, 18]. In the Stepanov study, (S)-NNN comprised $57 \pm 4 \%$ of total NNN in the conventional moist snuff products (versus $56 \%$ in urine) and $67 \pm 5 \%$ in the analyzed cigarettes (versus $67 \%$ in urine).

Our results are consistent with the simplest assumption regarding the enantiomeric composition of NNN in the urine of people who use tobacco products: that this unmetabolized NNN should have the same enantiomeric composition as the NNN in the product, since it is passing through the system unmetabolized. However, further consideration of possible contributing factors indicates potentially more complex mechanisms. NNN is absorbed primarily through the respiratory tract and lung in cigarette smokers, but through the oral cavity and digestive tract in smokeless tobacco users. In both cases, hepatic metabolism is likely dominant, and P450 2A6 has been established as the major catalyst of NNN $5^{\prime}$-hydroxylation, thought to be a quantitatively significant pathway in humans [11,23]. Since the dose of NNN per unit of tobacco in a smoker or smokeless tobacco user is relatively low, and the metabolism of NNN by P450 $2 \mathrm{~A} 6$ is efficient, it is somewhat surprising that any NNN is excreted unchanged, and it has been estimated that this comprises only about $1 \%$ of the NNN dose in smokers [12]. The excretion of unchanged NNN may be a consequence of inhibition of NNN metabolism by nicotine, which has been demonstrated previously, although the stereochemical aspects are unclear [24]. Furthermore, $5^{\prime}$-hydroxylation of NNN is believed to be the more prevalent metabolic pathway compared to $2^{\prime}$-hydroxylation in humans $[25,26]$. Human P450 2A6 is 8-fold more efficient at catalyzing the $5^{\prime}$-hydroxylation of $(S)$-NNN than $(R)$-NNN [11]. ( $\left.S\right)$-NNN also forms more total DNA adducts than $(R)$-NNN in both human hepatocytes and DNA incubated with human liver S9 enzymes [23]. Therefore, one might expect to observe more metabolism of $(S)$-NNN, leaving more unchanged $(R)$-NNN in human urine, but this is not consistent with our observations. Further studies are necessary to fully elaborate the pathways of NNN metabolism in humans. 


\section{Conclusions}

We have developed a chiral stationary phase LC-NSI-HRMS/MS method to separate and quantitate low ppt quantities of NNN enantiomers in human urine. ( $S$ )-NNN accounts for 67 $\pm 5 \%$ of total NNN in cigarette smokers' urine, and $56 \pm 3 \%$ in the urine of smokeless tobacco users using conventional moist snuff products. These values are the same as the enantiomeric composition of NNN in the original tobacco products used. This is the first study to use chiral stationary phase LC-NSI-HRMS/MS to quantify enantiomeric metabolites in human urine.

\section{Acknowledgments}

Funding

This work was supported by the National Cancer Institute [grant number R01-CA081301] and by a supplement from the U.S. Food and Drug Administration. Mass spectrometry was carried out in the Analytical Biochemistry Shared Resource of the Masonic Cancer Center, University of Minnesota, funded in part by a National Cancer Institute Cancer Center Support Grant [grant number P01-CA77598].

We thank Dr. Peter W. Villalta and Xun Ming for mass spectrometry assistance in the Analytical Biochemistry Shared Resource at the Masonic Cancer Center. We thank Nicole Thomson and Professor Sharon E. Murphy for providing nornicotine data, Dr. Pramod Upadhyaya for providing enantiomerically pure $(S)$ - and $(R)$-NNN, and Bob Carlson for editorial assistance. Jing Yang thanks Dr. Adam T. Zarth and Professor Irina Stepanov for helpful discussions and suggestions. The Pirkle Covalent $(S, S)$-Whelk-O1 $5 \mu \mathrm{m}$ Kromasil bulk material was a kind gift from Regis Technologies.

\section{Abbreviations}

\section{NNN \\ $N^{\prime}$-nitrosonornicotine}

LC-NSI-HRMS/MS liquid chromatography-nanoelectrospray ionization-high resolution tandem mass spectrometry

\section{References}

1. International Agency for Research on Cancer. Personal Habits and Indoor Combustions - A Review of Human Carcinogens, IARC Monographs on the Evaluation of Carcinogenic Risks to Humans. IARC; Lyon, FR: 2012.

2. Hecht SS. Biochemistry, biology, and carcinogenicity of tobacco-specific $N$-nitrosamines. Chem Res Toxicol. 1998; 11:559-603. [PubMed: 9625726]

3. Yuan JM, Knezevich AD, Wang RW, Gao YT, Hecht SS, Stepanov I. Urinary levels of the tobaccospecific carcinogen $N^{\prime}$-nitrosonornicotine and its glucuronide are strongly associated with esophageal cancer risk in smokers. Carcinogenesis. 2011; 32:1366-1371. [PubMed: 21734256]

4. Hecht SS, Chen CB, Hirota N, Ornaf RM, Tso TC, Hoffmann D. Tobacco-specific nitrosamines: formation from nicotine in vitro and during tobacco curing and carcinogenicity in strain A mice. $\mathrm{J}$ Natl Cancer Inst. 1978; 60:819-824. [PubMed: 633391]

5. Cai B, Ji H, Fannin FF, Bush LP. Contribution of nicotine and nornicotine toward the production of $N^{\prime}$-nitrosonornicotine in air-cured tobacco (nicotiana tabacum). J Nat Prod. 2016; 79:754-759. [PubMed: 26959866]

6. Carmella SG, McIntee EJ, Chen ML, Hecht SS. Enantiomeric composition of $N^{\prime}$-nitrosonornicotine and $N^{\prime}$-nitrosoanatabine in tobacco. Carcinogenesis. 2000; 21:839-843. [PubMed: 10753225]

7. Stepanov I, Yershova K, Carmella S, Upadhyaya P, Hecht SS. Levels of $(S)$ - $N^{\prime}$-nitrosonornicotine in U.S. tobacco products. Nicotine Tob Res. 2013; 15:1305-1310. [PubMed: 23212437] 
8. Balbo S, James-Yi S, Johnson CS, O’Sullivan MG, Stepanov I, Wang MY, Bandyopadhyay D, Kassie F, Carmella S, Upadhyaya P, Hecht SS. $(S)$ - $N^{\prime}$-Nitrosonornicotine, a constituent of smokeless tobacco, is a powerful oral cavity carcinogen in rats. Carcinogenesis. 2013 ; 34:21782183. [PubMed: 23671129]

9. McIntee EJ, Hecht SS. Metabolism of $N^{\prime}$-nitrosonornicotine enantiomers by cultured rat esophagus and in vivo in rats. Chem Res Toxicol. 2000; 13:192-199. [PubMed: 10725116]

10. Murphy SE, Isaac IS, Ding XX, McIntee EJ. Specificity of cytochrome P450 2A3-catalyzed alphahydroxylation of $N^{\prime}$-nitrosonornicotine enantiomers. Drug Metab Dispos. 2000; 28:1263-1266. [PubMed: 11038149]

11. Wong HL, Murphy SE, Hecht SS. Cytochrome P450 2A-catalyzed metabolic activation of structurally similar carcinogenic nitrosamines: $N^{\prime}$-nitrosonornicotine enantiomers, $N$ nitrosopiperidine, and $N$-nitrosopyrrolidine. Chem Res Toxicol. 2005; 18:61-69. [PubMed: 15651850]

12. Urban M, Scherer G, Kavvadias D, Hagedorn HW, Feng SX, Serafin R, Kapur S, Muhammad R, Jin Y, Mendes P, Roethig H. Quantitation of $N^{\prime}$-nitrosonornicotine (NNN) in smokers' urine by liquid chromatography-tandem mass spectrometry. J Anal Toxicol. 2009; 33:260-265. [PubMed: 19671245]

13. Stepanov I, Hecht SS. Tobacco-specific nitrosamines and their pyridine- $N$-glucuronides in the urine of smokers and smokeless tobacco users. Cancer Epidemiol Biomarkers Prev. 2005; 14:885891. [PubMed: 15824160]

14. Kavvadias D, Scherer G, Cheung F, Errington G, Shepperd J, McEwan M. Determination of tobacco-specific $N$-nitrosamines in urine of smokers and non-smokers. Biomarkers. 2009; 14:547553. [PubMed: 19747086]

15. Kotandeniya D, Carmella SG, Pillsbury ME, Hecht SS. Combined analysis of $N^{\prime}-$ nitrosonornicotine and 4-(methylnitrosamino)-1-(3-pyridyl)-1-butanol in the urine of cigarette smokers and e-cigarette users. J Chromatogr B Analyt Technol Biomed Life Sci. 2015; 1007:121126.

16. Stepanov I, Carmella SG, Briggs A, Hertsgaard L, Lindgren B, Hatsukami D, Hecht SS. Presence of the carcinogen $N^{\prime}$-nitrosonornicotine in the urine of some users of oral nicotine replacement therapy products. Cancer Res. 2009; 69:8236-8240. [PubMed: 19843845]

17. McCorquodale EM, Boutrid H, Colyer CL. Enantiomeric separation of $N^{\prime}$-nitrosonornicotine by capillary electrophoresis. Anal Chim Acta. 2003; 496:177-184.

18. Hatsukami DK, Stepanov I, Severson H, Jensen JA, Lindgren BR, Horn K, Khariwala SS, Martin J, Carmella SG, Murphy SE, Hecht SS. Evidence supporting product standards for carcinogens in smokeless tobacco products. Cancer Prev Res. 2015; 8:23-29.

19. Douglass ML, Kabacoff BL, Anderson GA, Cheng MC. Chemistry of nitrosamine formation, inhibition and destruction. J Soc Cosmet Chem. 1978; 29:581-606.

20. von Weymarn LB, Thomson NM, Donny EC, Hatsukami DK, Murphy SE. Quantitation of the minor tobacco alkaloids nornicotine, anatabine, and anabasine in smokers' urine by high throughput liquid chromatography-mass spectrometry. Chem Res Toxicol. 2016; 29:390-397. [PubMed: 26825008]

21. Erny GL, Cifuentes A. Liquid separation techniques coupled with mass spectrometry for chiral analysis of pharmaceuticals compounds and their metabolites in biological fluids. J Pharm Biomed Anal. 2006; 40:509-515. [PubMed: 16326060]

22. Nie YF, Liu XM, Yang XM, Zhao ZX. Review: Recent application of chiral liquid chromatography-tandem mass spectrometric methods for enantiomeric pharmaceutical and biomedical determinations. J Chromatogr Sci. 2013; 51:753-763. [PubMed: 23315149]

23. Zarth AT, Upadhyaya P, Yang J, Hecht SS. DNA adduct formation from metabolic $5^{\prime}$ hydroxylation of the tobacco-specific carcinogen $N^{\prime}$-nitrosonornicotine in human enzyme systems and in rats. Chem Res Toxicol. 2016; 29:380-389. [PubMed: 26808005]

24. Murphy SE, Heiblum R. Effect of nicotine and tobacco-specific nitrosamines on the metabolism of $N^{\prime}$-nitrosonornicotine and 4-(methylnitrosamino)-1-(3-pyridyl)-1-butanone by rat oral tissue. Carcinogenesis. 1990; 11:1663-1666. [PubMed: 2205411] 
25. Patten CJ, Smith TJ, Friesen MJ, Tynes RE, Yang CS, Murphy SE. Evidence for cytochrome P450 2A6 and 3A4 as major catalysts for $N^{\prime}$-nitrosonornicotine alpha-hydroxylation by human liver microsomes. Carcinogenesis. 1997; 18:1623-1630. [PubMed: 9276639]

26. Staretz ME, Murphy SE, Patten CJ, Nunes MG, Koehl W, Amin S, Koenig LA, Guengerich FP, Hecht SS. Comparative metabolism of the tobacco-related carcinogens benzo[a]pyrene, 4(methylnitrosamino)-1-(3-pyridyl)-1-butanone, 4-(methylnitrosamino)-1-(3-pyridyl)-1-butanol and $N^{\prime}$-nitrosonornicotine in human hepatic microsomes. Drug Metab Dispos. 1997; 25:154-162. [PubMed: 9029045] 


\section{Highlights}

- $\quad$ An LC-NSI-HRMS/MS method was developed to quantify NNN enantiomers in human urine.

- $\quad\left[\right.$ Pyridine- $\left.\mathrm{D}_{4}\right]$ nornicotine was used to monitor artifactual formation of NNN.

- $\quad(S)$-NNN, the more carcinogenic enantiomer, predominated in human urine.

- The enantiomeric ratio in urine was remarkably similar to that in tobacco products.

- This is the first use of NSI-HRMS for chiral separation of urinary metabolites. 


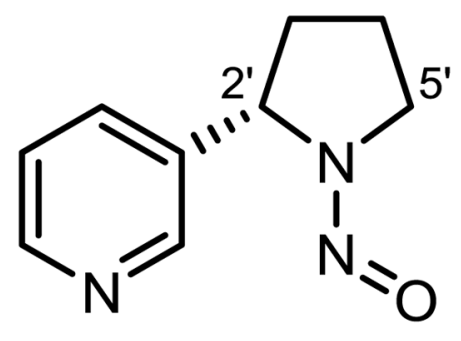

(S)-NNN (1)

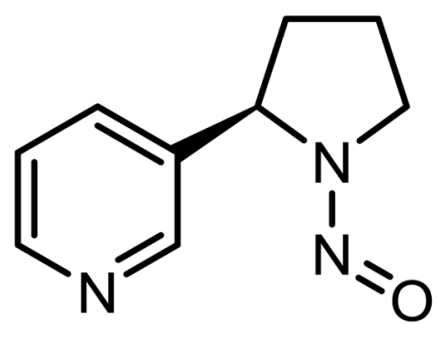

$(R)-\mathrm{NNN}(2)$

Figure 1.

Structures of $(S)$-NNN (1) and (R)-NNN (2). 

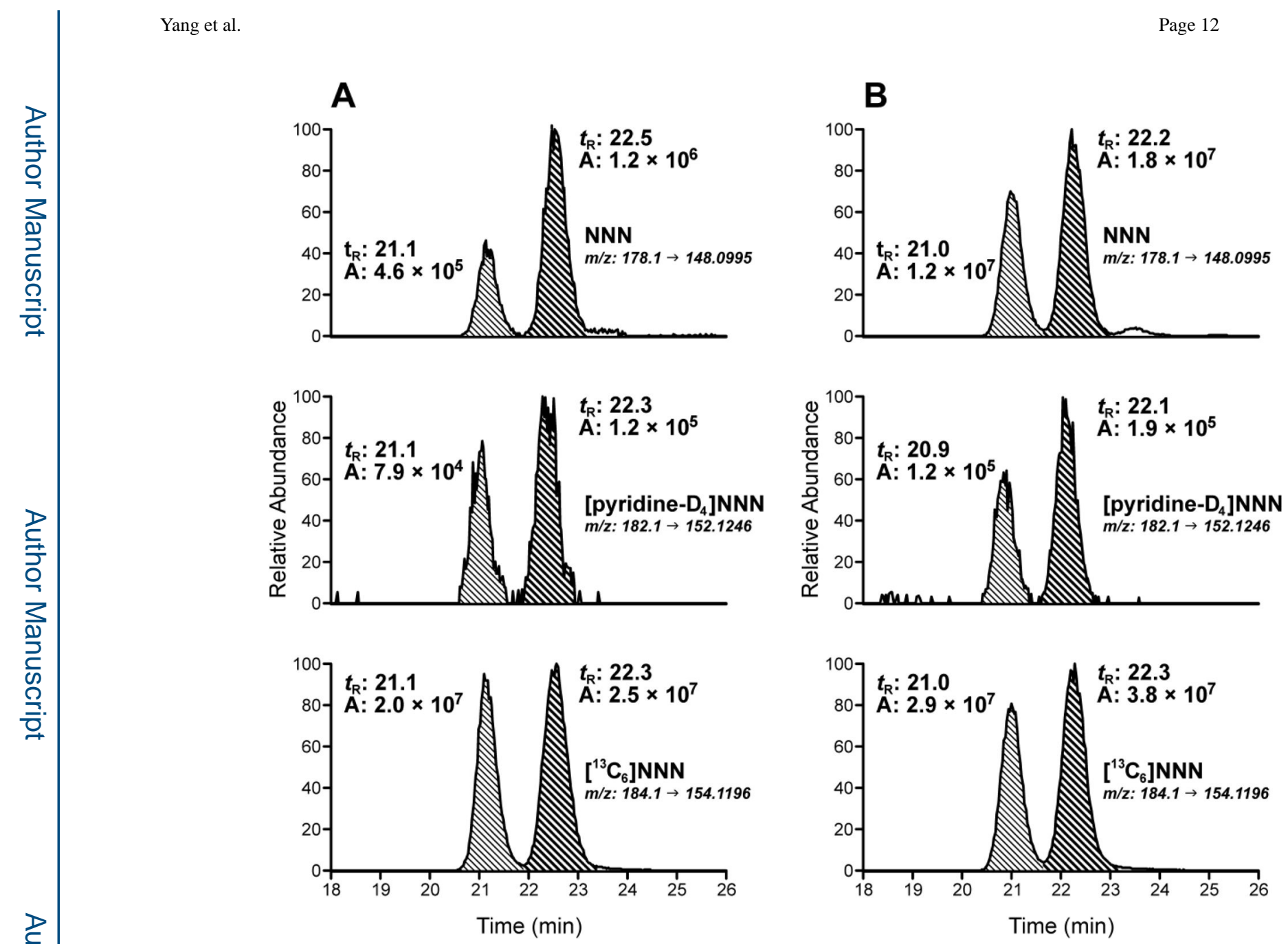

Figure 2.

Typical LC-NSI-HRMS/MS chromatograms of urine samples from (A) cigarette smokers and (B) smokeless tobacco users. The following ion transitions were monitored with accurate mass extracted: $m / z 178.1$ to 148.0995 for NNN (top trace), $m / z 182.1$ to 152.1246 for [pyridine- $\mathrm{D}_{4}$ ] NNN (middle trace), and $\mathrm{m} / z 184.1$ to 154.1196 for $\left[{ }^{13} \mathrm{C}_{6}\right] \mathrm{NNN}$ (bottom trace). $(R)$-NNN eluted at $21 \mathrm{~min}$ and $(S)-\mathrm{NNN}$ at $22 \mathrm{~min}$. $t_{\mathrm{R}}$ : retention time, A: peak area. 


\section{Table 1}

Urinary NNN enantiomer composition in cigarette smokers and smokeless tobacco users.

\begin{tabular}{|l|l|l|l|}
\hline & Cigarette Smokers $(\boldsymbol{n}=\mathbf{2 0})$ & Smokeless Tobacco Users $^{\boldsymbol{a}}(\boldsymbol{n}=\mathbf{1 0})$ & $\boldsymbol{p}$-value $\boldsymbol{b}$ \\
\hline Total NNN (fmol/mL) & $20.5 \pm 27.1$ & $67.1 \pm 56.7$ & 0.005 \\
\hline$($ Range $)$ & $(4.3-120.4)$ & $(24.8-200.4)$ & \\
\hline$($ S)-NNN \% & $67 \pm 5 \%$ & $56 \pm 3 \%$ & $<0.001$ \\
\hline (Range) & $(61-79 \%)$ & $(52-59 \%)$ & \\
\hline
\end{tabular}

${ }^{a}$ Only conventional moist snuff users are included. The $\%(S)$-NNN in the two Camel snus users is reported in the text.

$b$ The two-tailed $t$-test was used and a $p$ value $<0.05$ was considered statistically significant. 